\title{
Structural Integrity Assessment of Superheater Outlet Penetration Tubeplate Haofeng Chen ${ }^{a,{ }^{*}}$ and Alan R.S. Ponter ${ }^{b}$ \\ ${ }^{a}$ Department of Mechanical Engineering, University of Strathclyde, Glasgow, G1 1XJ, UK \\ ${ }^{\mathbf{b}}$ Department of Engineering, University of Leicester, Leicester, LE1 7RH, UK
}

\begin{abstract}
In recent years, the Linear Matching Method (LMM) has been well developed for the integrity assessment of the component subjected to cyclic thermal and mechanical loads. In this paper, the fatigue damage of a superheater outlet penetration tubeplate is assessed in detail using the LMM with an ABAQUS 3D finite element model. The significant thermal transients of the component are due to the out of phase steam temperature oscillations. The primary loading on the component is from pressure (steam and gas) and system moment on the penetration and tailpipes. A transient thermal analysis is performed in the first step to determine the component temperature history during the cycle. Then these temperature solutions are used as an input to the structural analysis to obtain the elastic stress history caused by these temperature loads. A shakedown analysis is thereafter carried out and the evaluation of the steady cyclic behaviour of tubeplate during the steady state cycle is then achieved using the LMM. The elastic, plastic and total strain ranges over the steady state cycle are evaluated for the fatigue damage assessment. Both the constant and changing residual stress solutions associated with the steady state cycle are obtained. The comparisons of stress and strain range calculations for out of phase temperature oscillations by the LMM and other methodologies are given in the paper. Finally, a LMM ratchet limit analysis is carried out to assess the capacity of the component subjected to the existing thermal transients to withstand an additional primary loads including both pressure and moment. The temperature dependent elastic-plastic properties are adopted throughout the LMM assessment.
\end{abstract}

Keywords: Structural integrity; Shakedown analysis; Fatigue damage; Steady state cycle

\footnotetext{
* Corresponding author.

Email: haofeng.chen@strath.ac.uk

Tel. +44 $1415482036 \quad$ Fax. +441415525105
} 


\section{Introduction}

In the past decades, British Energy Generation Ltd (BEGL)'s R5 integrity assessment procedure [1] has been widely used in routine integrity assessments for the high temperature response of structures. In order to understand the relationship between a range of possible failure modes and the history of temperature and of mechanical loading, R5 makes use of insight provided by structural mechanics and expressed in terms of a range of failure laws and rules that form the fabric of design codes and life assessment methods. The calculations in R5 [1] are based largely on the so-called reference stress technique and yield the elastic and shakedown solutions with good convenience and efficiency. However, in order to improve the accuracy, these rule based methods in R5 have to be supplemented by the detailed simulation of behaviour using complex constitutive equation. For most cases, the detailed simulation technique with full step-by-step evolutive elasticplastic analysis may be too complex and time-consuming to gain the required solutions.

There has been a recent trend towards the development of new methodologies that combine the convenience and efficiency of rule based methods and the accuracy of simulation techniques. The developments that form the basis for this application began, in the early 1990's as an exploration of computational methods that are capable of providing highly accurate limit load solutions for problems of structural components containing cracks, as an input to the life assessment methods. The success of this early work indicated that there is a class of computational techniques already in existence that had the capacity for development into generalised direct methods. The basis of these methods is through the simple idea of representing histories of stress and inelastic strain as the solution of a linear problem where the linear moduli are allowed to vary both spatially and in time. The progenitors of such techniques are the Reduced Modulus Method of Marriot [2], the GLOSS method of Sheshadri [3] and the Elastic Compensation Method [4]. These developments have recently been reviewed by Mackenzie, Boyle and Hamilton [5]. These methods were viewed as simple methods of producing approximations to inelastic problems but without a particularly secure theoretical foundation.

In recent years, on the basis of previous developed ECMs, a new simplified and generalised analysis method, the Linear Matching Method (LMM), has subsequently been developed by Ponter and Chen [6-17]. The LMM adopts the linear representation but applies it to structural problems through a well-defined theoretical structure. A sequence of linear problems is defined that give strain rate histories that give rise to equilibrium residual stress fields. Sequentially the correct non-linear constitutive assumptions are imposed. This 
is achieved by posing the problem as a minimum problem where the desired solution is the minimum of a functional of the strain rate history. Expressed in this way the method has the character of a non-linear programming method, with each step involving the solution of a linear problem that has most of the characteristics of problem to be solved. When implemented in a finite element code the method seeks out the solution that provides the minimum amongst the class of displacement fields described by the finite element mesh. In this way methods of great efficiency and flexibility can be devised where convergence proofs exist.

The LMM has been applied to a wide range of problems, including the ratchet limit of cracked bodies [6], the shakedown and ratchet limits of structural component subjected to thermo-mechanical loading for a von Mises yield condition [7-13]. This has included 3D holed plate problem [10, 11], rolling contact problem [12] and particulate metal matrix composite problem [13]. Corresponding to the typical life assessment procedure, the integrity assessments have been successfully made on a three-dimensional tube plate problem [10, 11] and a notched bar problem [14]. And moreover, the LMM has recently been extended to allow for the evaluation of plastic, creep and ratchet strains of structures subjected to a general load condition in a steady cyclic state [15$17]$.

In this paper, the newly developed assessment procedures [15-17] based on the Linear Matching Method have been used to evaluate superheater outlet penetration tubeplate fatigue damage from steam temperature oscillations. The component temperature history during the cycle is calculated by a transient thermal analysis. A shakedown analysis is thereafter carried out and the evaluation of the steady cyclic behaviour of tubeplate during the steady state cycle is then achieved using the LMM on the basis of an elastic stress history caused by both temperature and mechanical loads. The elastic, plastic and total strain ranges over the steady state cycle are evaluated for the fatigue damage assessment. A LMM ratchet limit analysis is also carried out to assess the capacity of the component subjected to the existing thermal transients to withstand an additional primary loads including both pressure and moment. The comparisons of calculated stress and strain range by the LMM and other methodologies demonstrate the applicability of the LMM. 


\section{Finite element model and load history}

An ABAQUS [18] 3D Finite Element (FE) model is generated for the assessment of the superheater outlet penetration tubeplate fatigue damage in both the LMM and the elastic-plastic step-by-step analysis. Fig. 1 gives the detailed information about the mesh arrangement and also shows the location of the maximum strain range. The finite element mesh consists of ABAQUS type C3D20R, twenty-node quadratic brick, reduced integration elements.

The primary loading on the component is from steam and gas pressure and system moments on the penetration and tailpipes. A schematic of the transient thermal loading history from the out of phase oscillations is given in Fig. 2, which produces the most significant stress and stress range in the superheater outlet penetration tubeplate subjected to the current working environment. Hence, this load cycle type is selected for the inelastic analysis. Other load cycle types with a smaller elastic stress range are expected to be encompassed in terms of cyclic behaviour.

\section{Material data}

The component is made from Type $316 \mathrm{H}$ austenitic stainless steel throughout. In order to calculate the thermal stress, a transient heat transfer analysis has been carried out to determine the temperature history during the cycle. The temperature dependent specific heat and thermal conductivity (Table 1) are adopted in the transient thermal analysis, where the density of the material equals to $7.966 \mathrm{~g} / \mathrm{cm}^{3}$. In the structural analysis, the Poisson's ratio has been taken to be a constant value of 0.29 . The coefficient of thermal expansion and the Young's modulus are considered to be temperature-dependent parameters, as shown in Table 1 and 2 . The yield stress of the material, which is given in Table 3 , is also considered to be temperature dependent.

\section{Transient heat transfer analysis and elastic analysis}

A temperature history from the out of phase oscillations has been calculated by a transient thermal analysis using temperature dependent thermal parameters. Figs. 3a-5a present the calculated temperature fields when 
operating at steady state normal operation, temperature ramping up to $540^{\circ} \mathrm{C}$ and ramping down to $380^{\circ} \mathrm{C}$, respectively. The corresponding elastic thermal stresses caused by these temperature loads are also giving in Figs $3 b, 4 b$ and $5 b$, respectively. The above three temperatures from the out of phase oscillations produce the most onerous elastic stress range during the cycle. Other load cycle types with a smaller elastic stress range are expected to be encompassed in terms of cyclic behaviour. Although other thermal loads with a smaller elastic stress could be ignored in the further assessment, in this paper, all thermal elastic stresses caused by the out of phase oscillation cycle are included as inputs to the further structural analyses.

The calculated gas and steam pressure stresses at the normal operation are presented in Figs. 6 and 7 , respectively. The primary loading on the component from pressure generates relatively small stress and these stresses do not contribute significantly to the stress range during the oscillations. Comparing with gas and steam pressure stresses, the elastic stress caused by the normal operating moment is more significant (Fig. 8). It can also be seen from Figs. 6-8 that the significant stresses caused by these primary loads mainly occur at the tailpipes. However, in general, thermal stresses from the out of phase oscillations are much more significant than these mechanical stresses.

\section{Elastic shakedown and plastic shakedown (ratchet limit) analysis}

The detailed numerical procedure for the traditional shakedown analysis using the Linear Matching Method was presented in [7]. In this calculation, the cyclic stress field is a sum of the linear elastic solutions, associated with the load history, and a constant residual stress field. The load history is applied through the linear solutions and the solved continuum solution, at each iteration, delivers a residual stress field instead of a stress field in equilibrium with an applied load. This strategy simplifies the implementation as well as being more flexible when defining load histories. The calculated converged values of elastic shakedown limit are plotted in Fig. 9 for the tubeplate subjected to either thermal loads from the out of phase oscillations or combined thermalmechanical loads. It can be seen that the effect of the primary loads on the elastic shakedown limit can be ignored, as the significant stresses and stress ranges arise from the transient thermal loading. For a superheater outlet penetration tubeplate subjected to current out of phase oscillation, the computed elastic shakedown limit multiplier by the LMM converges to 0.42 (Fig. 9). That means the applied out of phase oscillations produce a 
stress range far beyond the shakedown limit. Either reverse plasticity mechanism or ratchetting occurs in the component.

In order to evaluate the exact failure mechanism of the component, a detailed ratchet limit analysis has been performed using the LMM [8,9]. The calculation above shakedown consists of two stages. The first stage involves the evaluation of a changing residual stress history that brings the stress history within yield and also provides the plastic strain amplitude. The calculation is carried out for various history of elastic stress linearly scaled from the actual history. The second stage involves the evaluation of the ratchet limit by superimposing a constant load that takes the shakedown to the ratchet limit. In the case of superheater outlet penetration tubeplate, this load is taken as the primary load including both pressure and moment in the steady state normal operation. By this means a ratchet limit interaction diagram is created with one axis the scaled actual thermal history and the other the imposed primary load. The calculated shakedown limits and ratchet limits by the Linear Matching Method are presented in Fig.10, where the non-dimensional value in X-coordinate represents the applied additional primary load at the normal operation, and the non-dimensional value in Y-coordinate represents the applied cyclic thermal transient from out of phase oscillations. Note that the values of 1 on each axis correspond to the applied primary load and the actual thermal loading history, respectively. A rectangle shakedown region is found in Fig. 10, which means that there is no effect of the applied cyclic thermal transients on the capacity of the component to withstand an additional constant primary load to failure. The reason of the above phenomenon is obvious by analysing the failure mechanism (Fig. 11) and elastic stresses (Figs. 3-8) by both thermal and mechanical loads. The maximum elastic thermal stress range from out of phase oscillations occurs at node 3007 (Fig. 1) on the bore of one of the steam tubes near the mid plane of the tubeplate. However, it can be seen from Fig. 8 that the constant primary loading produces most significant stress only at certain location in one of the tailpipes. The location of the maximum mechanical stress from the primary loading is far away from the node 3007. In Fig. 11, the failure occurs at one of the tailpipe for the tubeplate subjected to an existed cyclic thermal loading to withstand an additional pressure and bending moment until collapse

\section{Steady cyclic plastic behaviour}


When the cyclic stress range of the structure is no longer within the elastic shakedown range, either reverse plasticity or ratchetting mechanism occurs. For the localised reverse plasticity, it is found empirically that the low cycle fatigue mechanism occurs and the number of cycles to failure may be determined by the maximum plastic strain range.

For cyclic problems, the cyclic stress history during a typical cycle $0 \leq t \leq \Delta t$, irrespective of material properties, may be expressed in terms of three components, the elastic solution, a transient solution accumulated up to the beginning of the cycle and a residual solution that represents the remaining changes within the cycle. The general form of the stress solution for cyclic problems involving changing residual stress fields is given by

$$
\sigma_{i j}\left(x_{i}, t\right)=\lambda \hat{\sigma}_{i j}\left(x_{i}, t\right)+\bar{\rho}_{i j}\left(x_{i}\right)+\rho_{i j}^{r}
$$

where $\bar{\rho}_{i j}$ denotes a constant residual stress field in equilibrium with zero surface tractions on $S_{T}$ and corresponds to the residual state of stress at the beginning and end of the cycle. $\rho_{i j}^{r}$ denotes the changing component of residual stress during the cycle and satisfies;

$$
\rho_{i j}^{r}\left(x_{i}, 0\right)=\rho_{i j}^{r}\left(x_{i}, \Delta t\right)=0
$$

If the above changing residual stress field $\rho_{i j}^{r}(t)$ is derived from a plastic strain rate history $\dot{\varepsilon}_{i j}^{p r}$ that satisfies the zero growth condition $\int_{0}^{\Delta t} \dot{\varepsilon}_{i j}^{p r} d t=0$ everywhere in $\mathrm{V}$, the reverse (alternating) plasticity mechanism occurs. When the changing residual stress field $\rho_{i j}^{r}(t)$ is derived from a plastic strain rate history $\dot{\mathcal{E}}_{i j}^{p r}$ that satisfies the growth condition $\int_{0}^{\Delta t} \dot{\varepsilon}_{i j}^{p r} d t=\Delta \varepsilon_{i j}^{p r}$ where $\Delta \varepsilon_{i j}^{p r}$ is a compatible accumulated strain giving rise to non-zero displacement increment, the ratchetting mechanism appears in the component.

The Linear Matching Method is capable of providing not only the shakedown and ratchet limits, but also the steady cyclic state solutions involving both residual stress fields $\bar{\rho}_{i j}, \rho_{i j}^{r}$ and strain ranges during the cycle with sufficient accuracy [17], using the same material data normally available for assessment procedure.

Fig. 12 gives the calculated contour of the total effective strain range during the steady state cycle by the LMM. Further investigations show that the most dangerous area includes node 3007 (Fig. 1) on the bore of one of the steam tubes near the mid plane of the tubeplate. The calculated LMM equivalent stress and strain ranges 
at node 3007 for out of phase temperature oscillations are further compared with solutions from the various calculation methods in Table 4. A R5 [1] State Variable (R5SV) model is adopted in both the elastic and inelastic analyses. A traditional elastic-perfectly plastic analysis and an assessment using R5 volume 2/3 method [1] have also been carried out. The order of these strain range values is as expected. It can be seen that the LMM equivalent stress and strain ranges are in good agreement with the ABAQUS inelastic R5SV solution.

Figs 13 (a) and (b) present the contour of the elastic and plastic effective strain ranges during the steady state cycle by the LMM respectively. A contour of the steady state strain increment per cycle (ratchetting strain) is also given in Fig 14. Compared with the elastic or plastic strain ranges, the ratchetting strain is insignificant and the magnitude is about $3 \%$ of the plastic strain range. The dominant failure in the tubeplate is caused by the low cycle fatigue, which is determined by the plastic strain range.

\section{Discussions}

As shown in Fig. 14, the calculated ratchetting strain is no more than 3\% of plastic strain range. Hence, the ratchetting strain can be ignored and the plastic strain is assumed to have settled into a closed cycle. It can be seen much clearer from Fig. 10 that the applied loading condition from the out of phase oscillations is in the reverse plasticity region. No ratchetting mechanism occurs. In fact, the ratchetting strain in Fig. 14 is produced by numerical errors within the LMM, as the LMM is a simplified approximate upper bound method.

The loading on the component is from pressure (steam and gas) and system moments on the penetration and tailpipes. These are shown in Figs. 6, 7 and 8 to generate relatively small stresses and also these do not contribute significantly to the stress range during the oscillations therefore these loads are ignored in the steady cyclic plastic behaviour analysis. And also for this particular loading history, the start of dwell stress for the out of phase oscillation cycle is small and at the steady state operation dwell temperature of $502{ }^{\circ} \mathrm{C}$ the creep relaxation is small. Therefore, this paper considers only the fatigue cycle and the contribution of creep to the failure is ignored.

The Linear Matching method adopted in this paper produces the consistent results with other assessment methods (Table 4) and proves its applicability and effectiveness. By the comparisons between the computational efforts involved in the LMM and full inelastic FE analysis, a fact can be drawn that the usage of 
LMM is much cheaper than full inelastic FE analysis, especially for the cyclic load condition. For this case with ten load extremes in one cycle, a typical LMM calculation normally involves approximately $300-400$ increments in the ABAQUS calculation to simulate the final steady stress state. However, when using ABAQUS full inelastic evolutive analysis, even if limited load cycles are calculated, the total number of increment will normally more than 10000. The second numerical difficulty involved in ABAQUS full inelastic analysis is the numerical convergence problem. Especially for the component with higher stress and strain in some local areas, e.g. the vicinity of the hole or the crack tip, it's always difficult to choose suitable control parameters to obtain final convergent results.

Using Linear Matching method, all parameters are computed at the integration points with good accuracy. However, the inaccurate values at nodes of component surface would be generated by the extrapolation method adopted by ABAQUS, if the mesh is insufficiently fine.

\section{Conclusions}

Linear Matching Method is capable of providing direct solutions to Life Assessment Methods with high computational efficiency and stability. These are the first stage of work on the transient thermal problem based upon the current data and FE model in hand. In the LMM analysis, all the elastic plastic material data are temperature dependent, which are consistent with those in R5SV model.

The LMM shakedown limit analysis provided a shakedown limit, i.e. reverse plasticity limit, with value of 0.42. That means the applied cyclic thermal transients is about twice the reverse plasticity limit. The plastic strain range/total strain range would be a critical parameter to determine the low cycle fatigue lifetime.

The obtained equivalent stress (458MPa) and strain $(0.52 \%)$ ranges by LMM are in good agreement with those (450MPa, $0.51 \%$ ) by inelastic R5SV model.

At the cyclic steady state, the ratchetting strain calculate by LMM is less than $3 \%$ of the plastic strain range. Hence the ratchetting strain could be ignored. In fact, this calculated ratchetting strain is mainly introduced by the inherent numerical errors of the LMM as an approximate upper bound method.

The existence of cyclic thermal transients does not reduce the capacity of the component to withstand an additional pressure and moment to failure. The failure introduced by pressure and moment occurs at one of the 
four tailpipes. The maximum total strain range introduced by cyclic thermal transients occurred at different location, node 3007 .

\section{Acknowledgements}

The authors gratefully acknowledge the support of British Energy Generation Ltd, University of Leicester and University of Strathclyde during the course of this work.

\section{References}

1. Ainsworth R.A. (editor), R5: Assessment Procedure for the High Temperature Response of Structures, Issue 3, British Energy Generation Ltd, 2003

2. D. L. Marriott, Evaluation of deformation or load control of stresses under inelastic conditions using elastic finite element stress analysis, Proc ASME Pressure Vessels and Piping Conference, Pittsburgh, Pennsylvania, (1988), PVP- 136, 3-9

3. R. Seshadri, The generalised local stress strain (GLOSS) analysis - theory and application. Trans ASME, J. Pressure Vessel Technology, 113,(1991), 219-227

4. D. Mackenzie, J. T. Boyle, A simple method of estimating shakedown loads for complex structures, Proc. ASME Pressure Vessel and Piping Conference, Denver, (1993), PVP-265, 89-94

5. D. Mackenzie, J.T. Boyle, R. Hamilton, The Elastic Compensation method for limit and shakedown analysis: a review. Journal of Strain Analysis, 35, (2000) 171- 188.

6. Habibullah, M.S., and Ponter, A.R.S., Ratchetting limits for cracked bodies subjected to cyclic loads and temperatures, Engineering Fracture Mechanics, v 72 (11), 2005, 1702-1716

7. Chen H. F. \& Ponter A.R.S., Shakedown and Limit Analyses for 3-D Structures Using the Linear Matching Method, International Journal of Pressure Vessels and Piping, Vol. 78(6), 443-451, 2001

8. Ponter A.R.S. \& Chen H. F., A minimum theorem for cyclic load in excess of shakedown, with application to the evaluation of a ratchet limit, European Journal of Mechanics, A/Solids, 20 (4), 539-553, 2001

9. Chen H. F. \& Ponter A.R.S., A Method for the Evaluation of a Ratchet Limit and the Amplitude of Plastic Strain for Bodies Subjected to Cyclic Loading, European Journal of Mechanics, A/Solids, 20 (4), 555-571, 2001 
10. Chen H. F. \& Ponter A.R.S., Integrity assessment of a 3D tubeplate using the linear matching method. Part 1. Shakedown, reverse plasticity and ratchetting, International Journal of Pressure Vessels and Piping, $82(2), 2005$, p $85-94$

11. Chen H. F. \& Ponter A.R.S., Integrity assessment of a 3D tubeplate using the linear matching method. Part 2: Creep relaxation and reverse plasticity, International Journal of Pressure Vessels and Piping, 82(2), 2005, p 95-104

12. Chen H. F. \& Ponter A.R.S., The Linear Matching Method for shakedown and limit analyses applied to rolling and sliding point contact problems, International Journal of Road Materials and Pavement Design, $6,9-30,2005$

13. Chen H. F and Ponter A.R.S., On the Behaviour of a Particulate Metal Matrix Composite Subjected to Cyclic Temperature and Constant Stress, Computational Materials Science, 34, 2005, p 425-441

14. Ponter A.R.S., Chen H. F, Willis M. and Evans J., Fatigue-Creep and Plastic Collapse of Notched Bars, Fatigue \& Fracture of Engineering Materials \& Structures, 27, 305-318, 2004

15. Chen H. F. and Ponter A.R.S., Application of the Linear Matching Method to the Integrity Assessment for the High Temperature Response of Structures, ASME Pressure Vessels and Piping Division (Publication) $P V P, \mathrm{v} 458,2003, \mathrm{p} 3-12$

16. Chen H. F. \& Ponter A.R.S., Methods for the Evaluation of Creep Relaxation and the Amplitude of Reverse Plastic Strain for Bodies Subjected to Cyclic Loading, ASME Pressure Vessels and Piping Division (Publication) PVP, v 459, 2003, p 155-164

17. Chen H. F. \& Ponter A.R.S., Linear Matching Method on the evaluation of plastic and creep behaviours for bodies subjected to cyclic thermal and mechanical loading, International Journal for Numerical Methods in Engineering, 2006; 68: p13-32

18. ABAQUS, User's Manual, Version 6.7, 2007 


\section{Captions}

Fig. 1 3D FE mesh and location of maximum strain range for out of phase oscillation

Fig. 2 Schematic of the elastic thermal loading history

Fig. 3 Superheater outlet penetration tubeplate at steady state normal operation: (a) temperature field $\left({ }^{\circ} \mathrm{C}\right)$; (b) elastic thermal stress

Fig. 4 Superheater outlet penetration tubeplate when the temperature ramp up to $540\left({ }^{\circ} \mathrm{C}\right)$ : (a) temperature field $\left({ }^{\circ} \mathrm{C}\right)$; (b) elastic thermal stress

Fig. 5 Superheater outlet penetration tubeplate when the temperature ramp down to $380\left({ }^{\circ} \mathrm{C}\right):(a)$ temperature field $\left({ }^{\circ} \mathrm{C}\right)$; (b) elastic thermal stress

Fig. 6 Elastic gas pressure stress at the normal operation

Fig. 7 Elastic steam pressure stress at the normal operation

Fig. 8 Elastic stress caused by normal operating moment at the normal operation

Fig. 9 Converged values of shakedown limit multiplier

Fig. 10 The shakedown limit and ratchet limit interaction curves for 3D tubeplate with cyclic loading condition

Fig. 11 The failure mechanisms for the tubeplate subjected to an existed cyclic thermal loading to withstand an additional pressure and bending moment until collapse

Fig.12 The contour of total strain range for the steady state cycle by $\operatorname{LMM}\left(\Delta \bar{\varepsilon}=\bar{\varepsilon}\left(t_{\max }\right)-\bar{\varepsilon}\left(t_{\min }\right)\right)$

Fig.13 The contour of elastic and plastic strain ranges for the steady state cycle by LMM

Fig.14 The contour of ratchetting strain over the steady state cycle by LMM

Table 1 Variation of the coefficient of thermal expansion with temperature

Table 2 Variation of Young's modulus $E$ with temperature

Table 3 Variation of $0.2 \%$ proof stress (MPa) with temperature

Table 4 Comparison of Stress and Strain Range Calculations for Out of Phase Temperature Oscillations (Node 3007) 


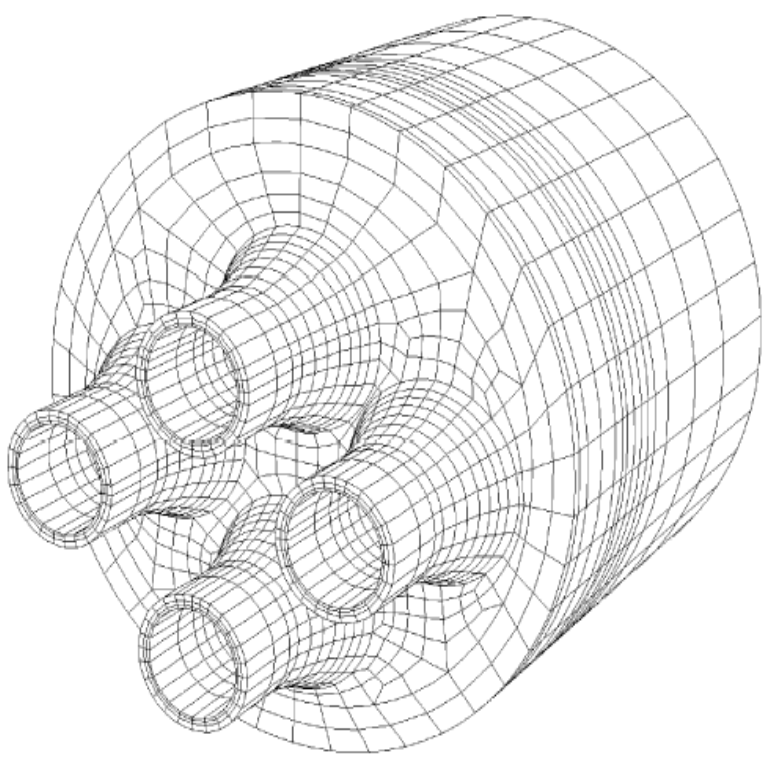

(a)

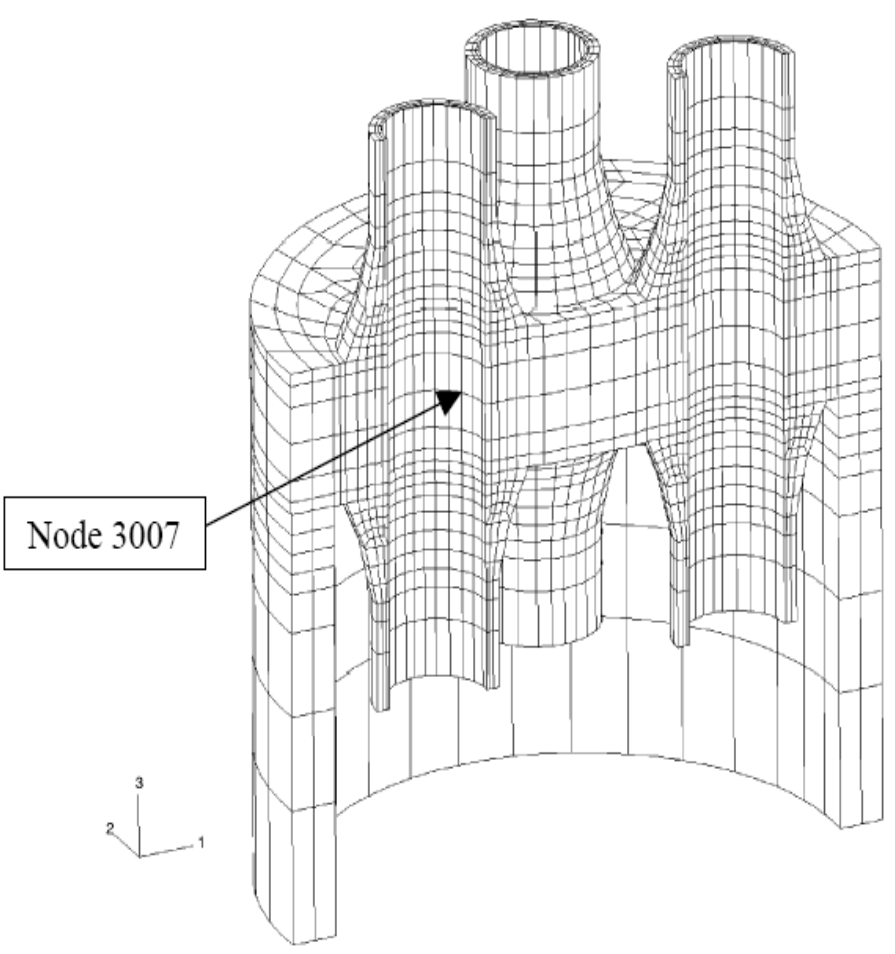

(b)

Fig. 1 3D FE mesh and location of maximum strain range for out of phase oscillation 


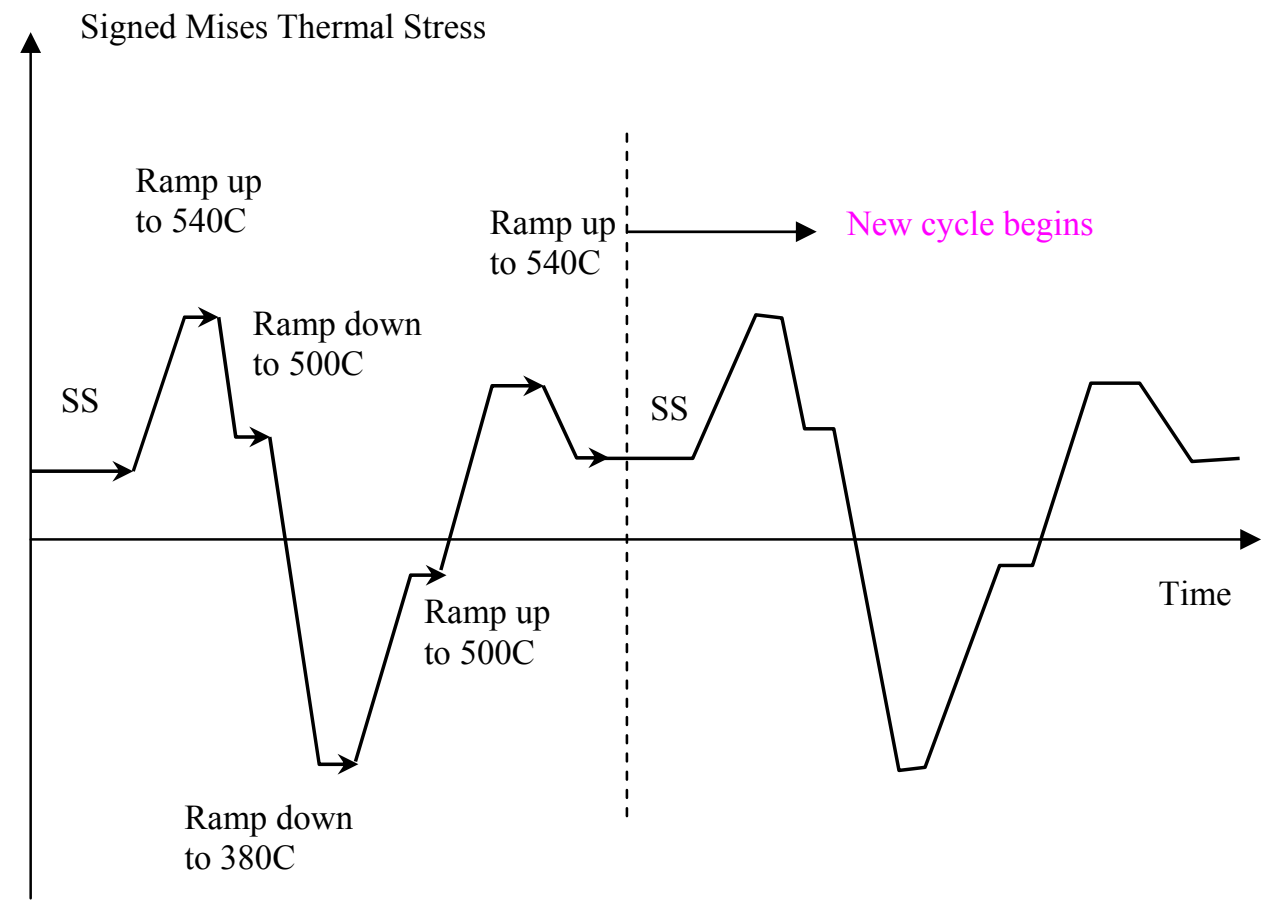

Fig. 2 Schematic of the elastic thermal loading history 

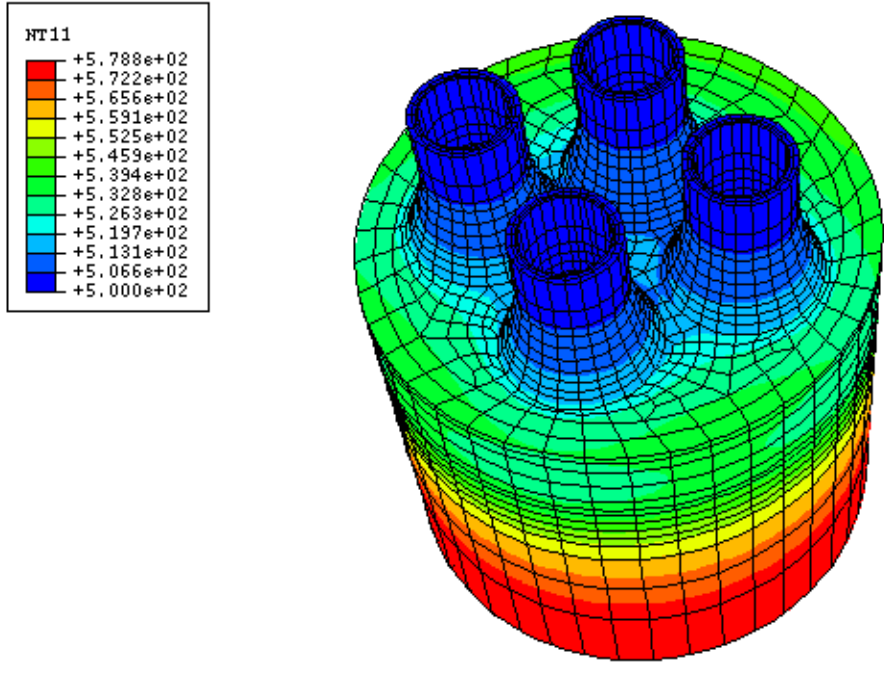

(a)
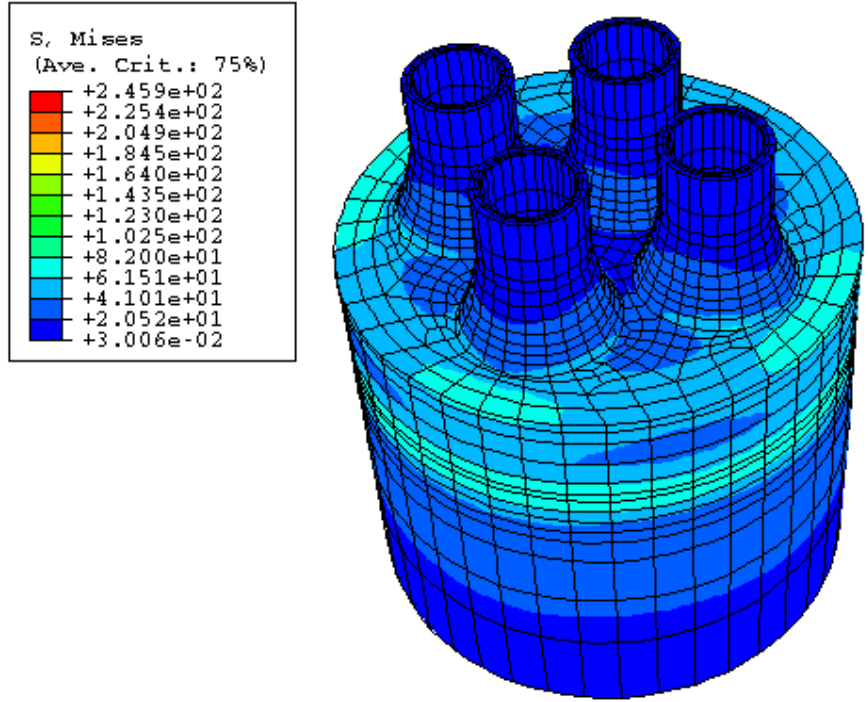

(b)

Fig. 3 Superheater outlet penetration tubeplate at steady state normal operation: (a) temperature field $\left({ }^{\circ} \mathrm{C}\right)$; (b) elastic thermal stress 

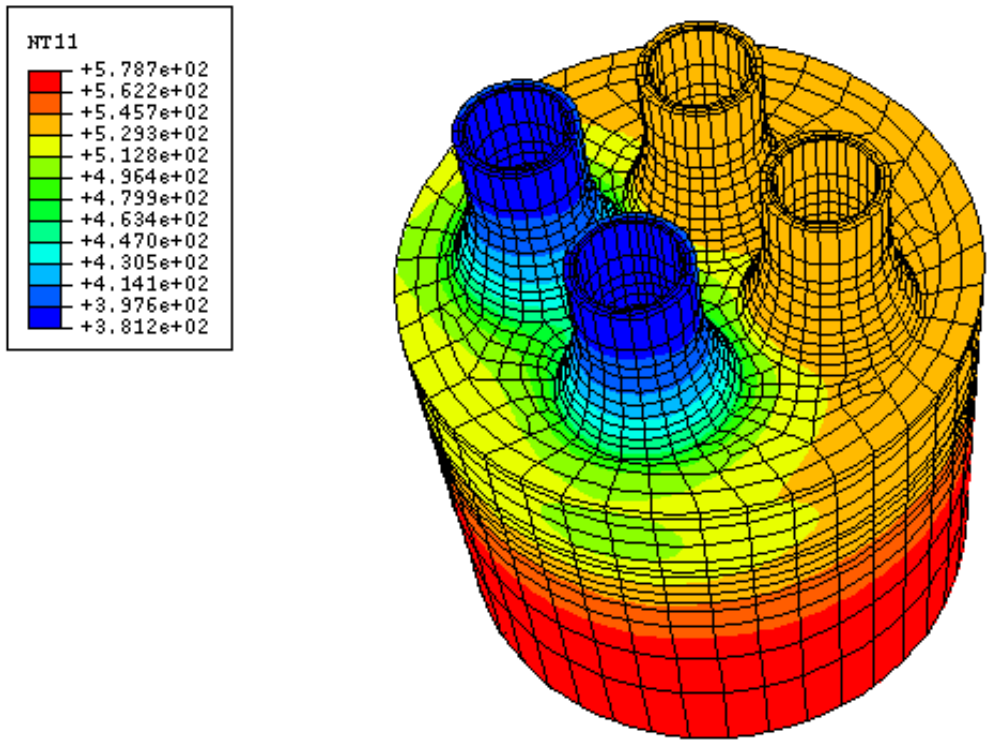

(a)
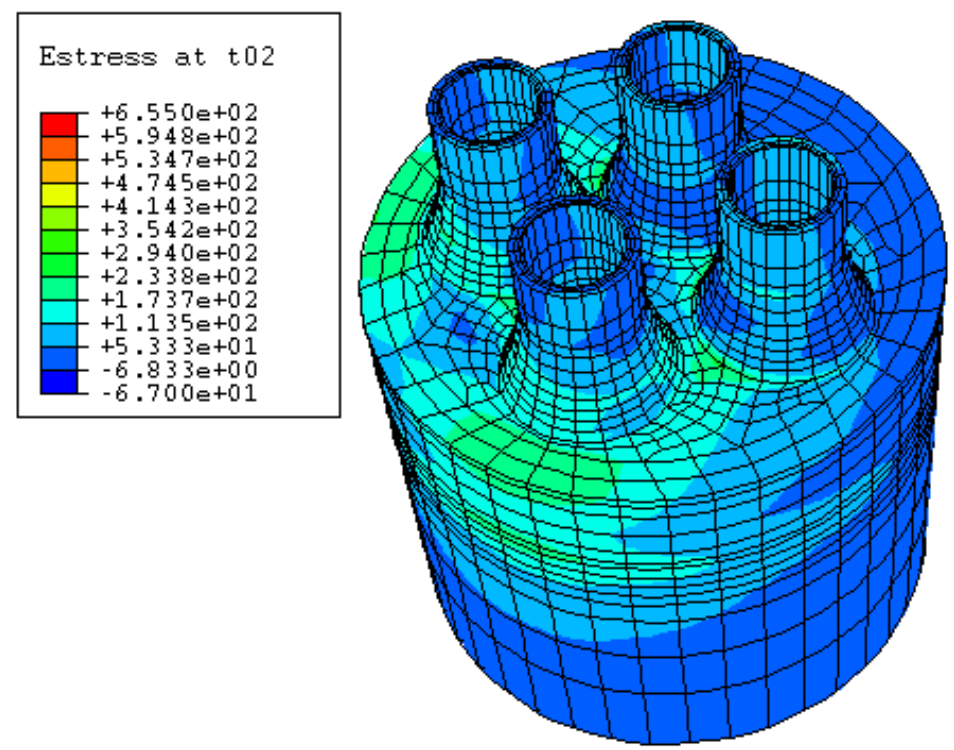

(b)

Fig. 4 Superheater outlet penetration tubeplate when the temperature ramp up to $540\left({ }^{\circ} \mathrm{C}\right):(a)$ temperature field $\left({ }^{\circ} \mathrm{C}\right)$; (b) elastic thermal stress 

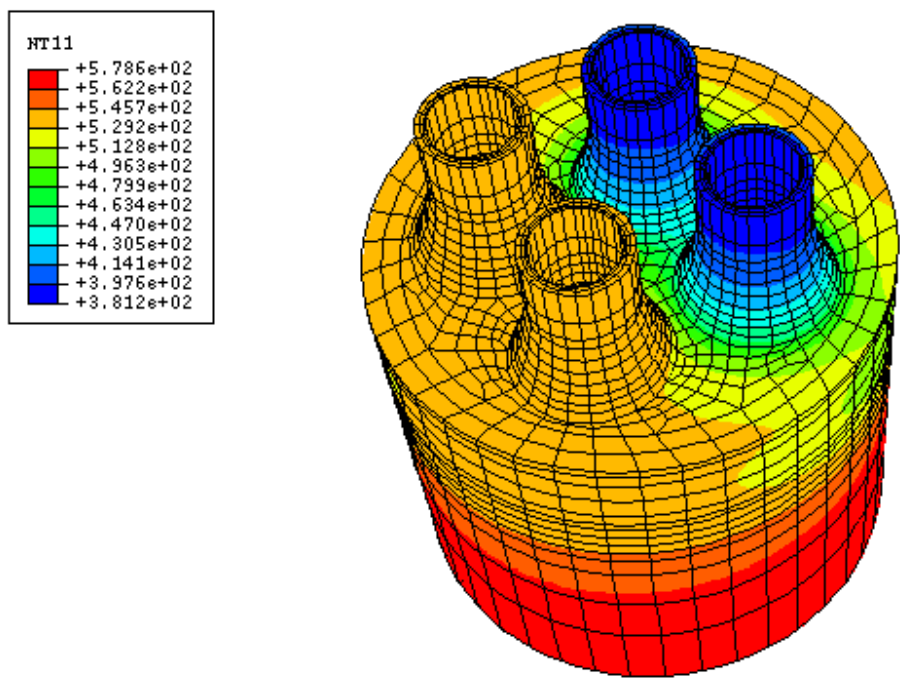

(a)
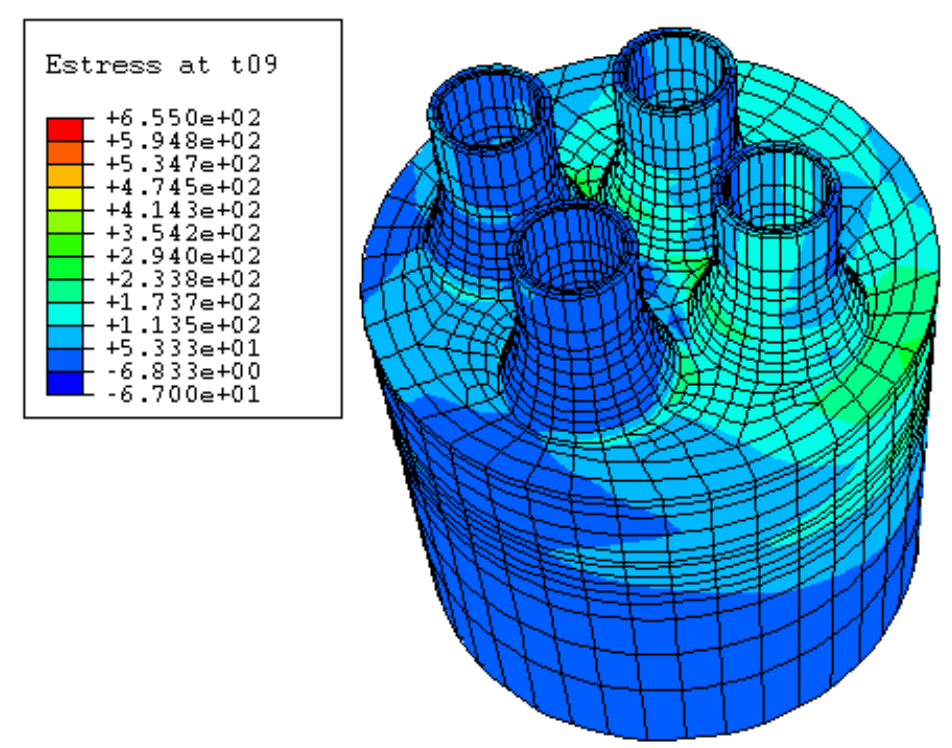

(b)

Fig. 5 Superheater outlet penetration tubeplate when the temperature ramp down to 380 ( ${ }^{\circ} \mathrm{C}$ ): (a) temperature field ( ${ }^{\circ} \mathrm{C}$ ); (b) elastic thermal stress 


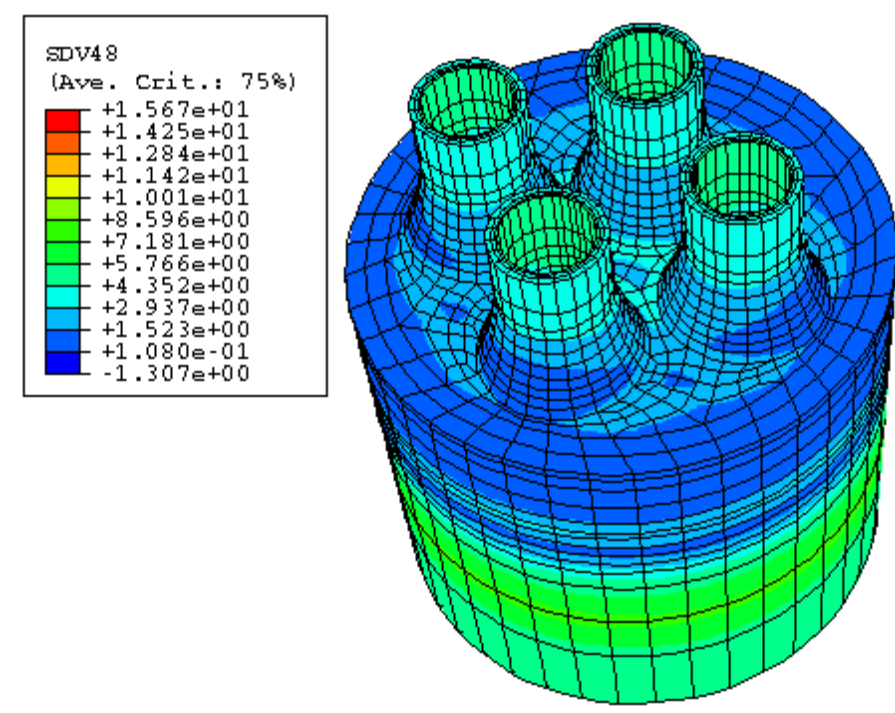

Fig. 6 Elastic gas pressure stress at the normal operation
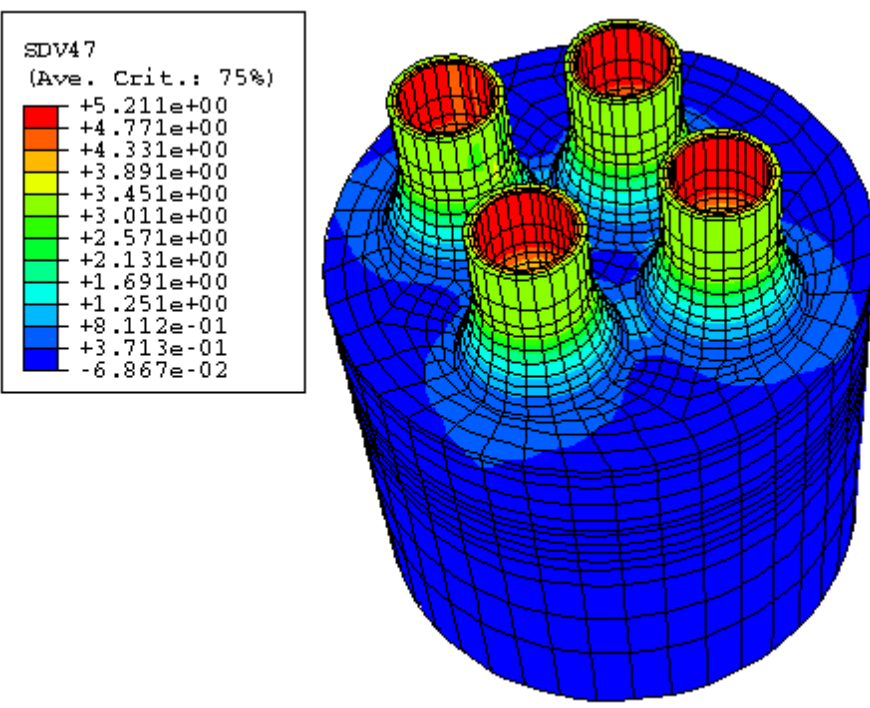

Fig. 7 Elastic steam pressure stress at the normal operation 

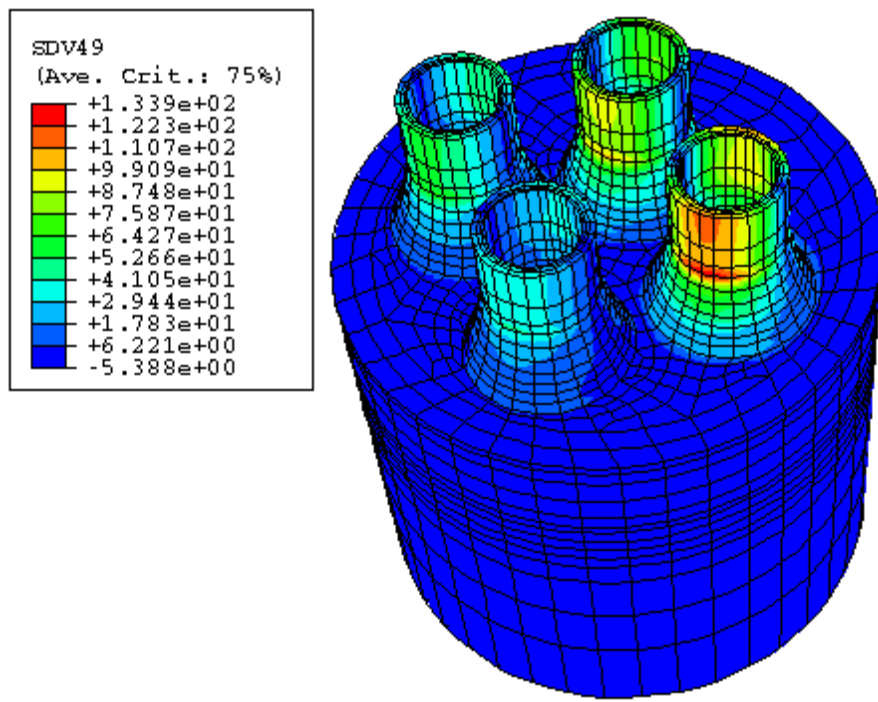

Fig. 8 Elastic stress caused by normal operating moment at the normal operation

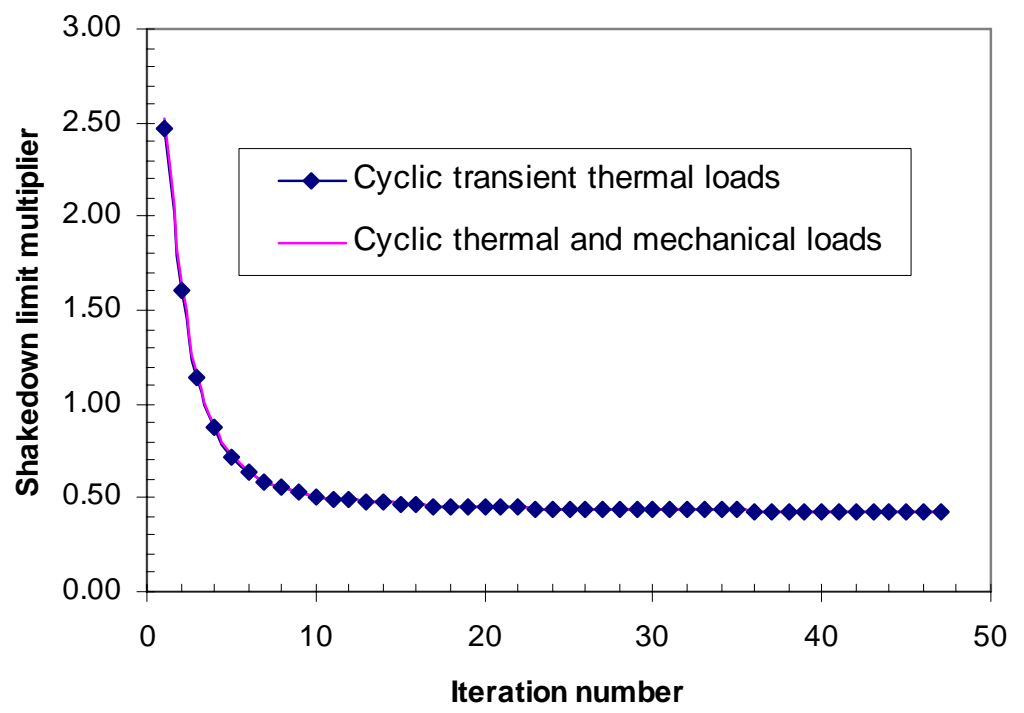

Fig. 9 Converged values of shakedown limit multiplier 
Applied cyclic thermal transients

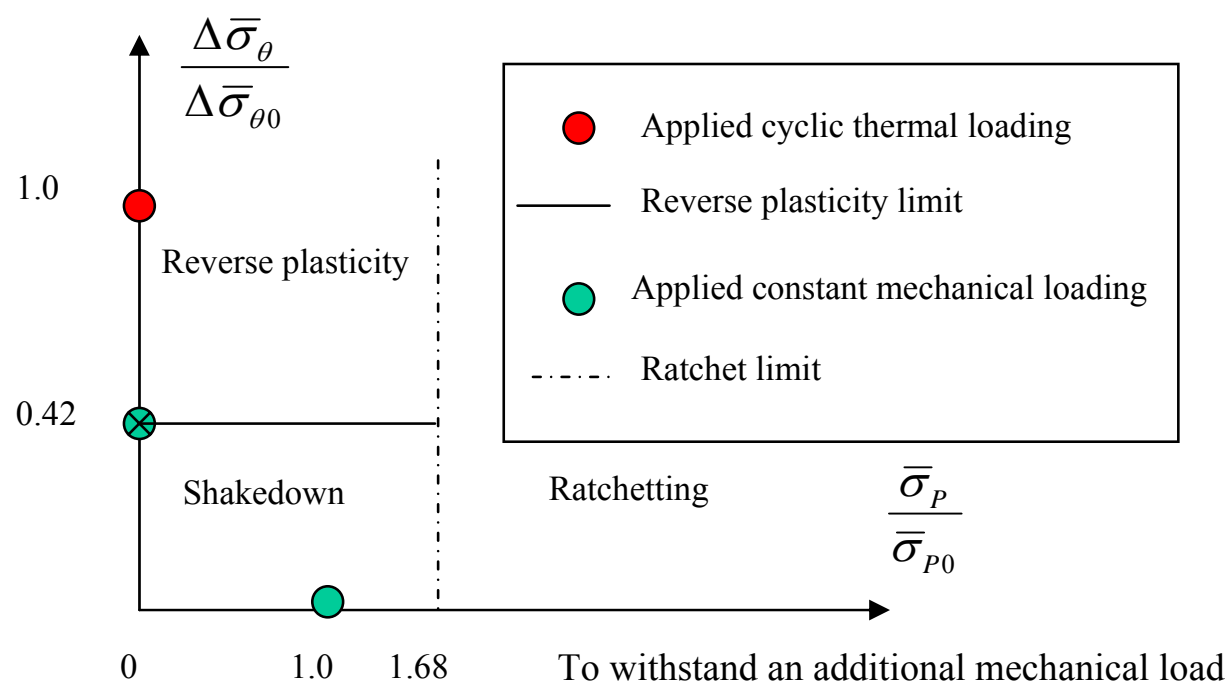

Fig. 10 The shakedown limit and ratchet limit interaction curves for 3D tubeplate with cyclic loading condition
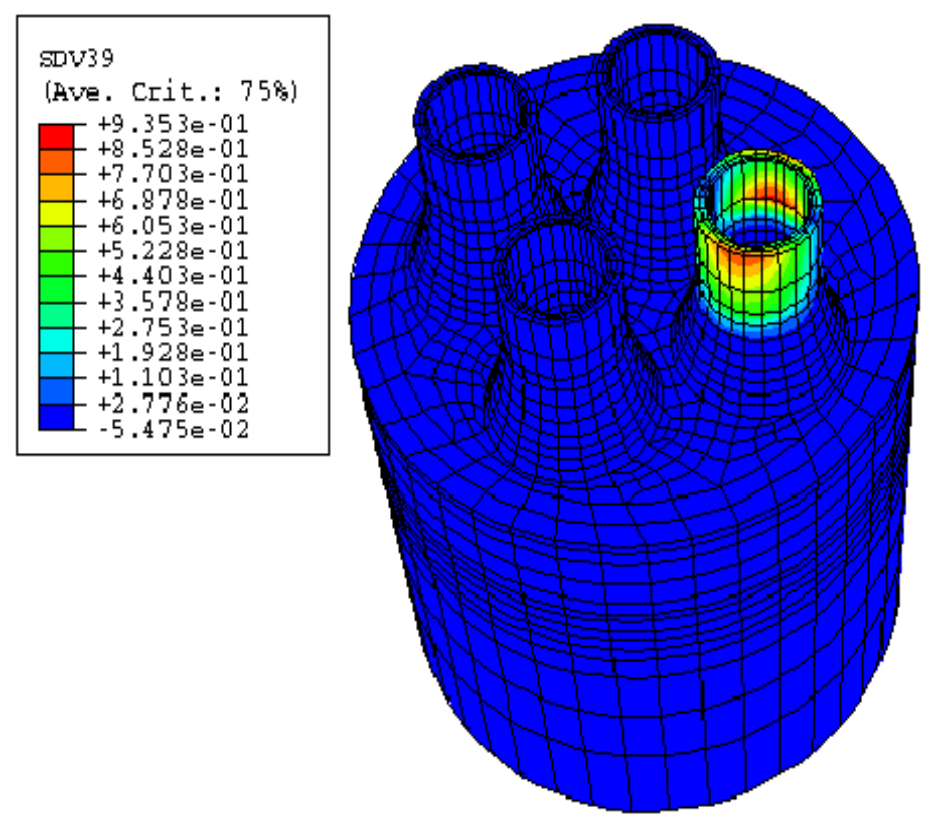

Fig. 11 The failure mechanisms for the tubeplate subjected to an existed cyclic thermal loading to withstand an additional pressure and bending moment until collapse 


\begin{tabular}{|c|}
\hline $\begin{array}{l}\text { SDvs0 } \\
\text { (Ave. Crit. : 758) } \\
\begin{array}{|l}+5.261 \mathrm{e}-03 \\
+4.709 \mathrm{e}-03 \\
++4.158 \mathrm{e}-03 \\
++3.606 \mathrm{e}-03 \\
++3.054 \mathrm{e}-03 \\
++2.502 \mathrm{e}-03 \\
+1.951 \mathrm{e}-03 \\
+1.399 \mathrm{e}-03 \\
++8.472 \mathrm{e}-04 \\
+2.955 \mathrm{e}-04 \\
-2.563 \mathrm{e}-04 \\
-8.080 \mathrm{e}-04 \\
-1.360 \mathrm{e}-03\end{array}\end{array}$ \\
\hline
\end{tabular}

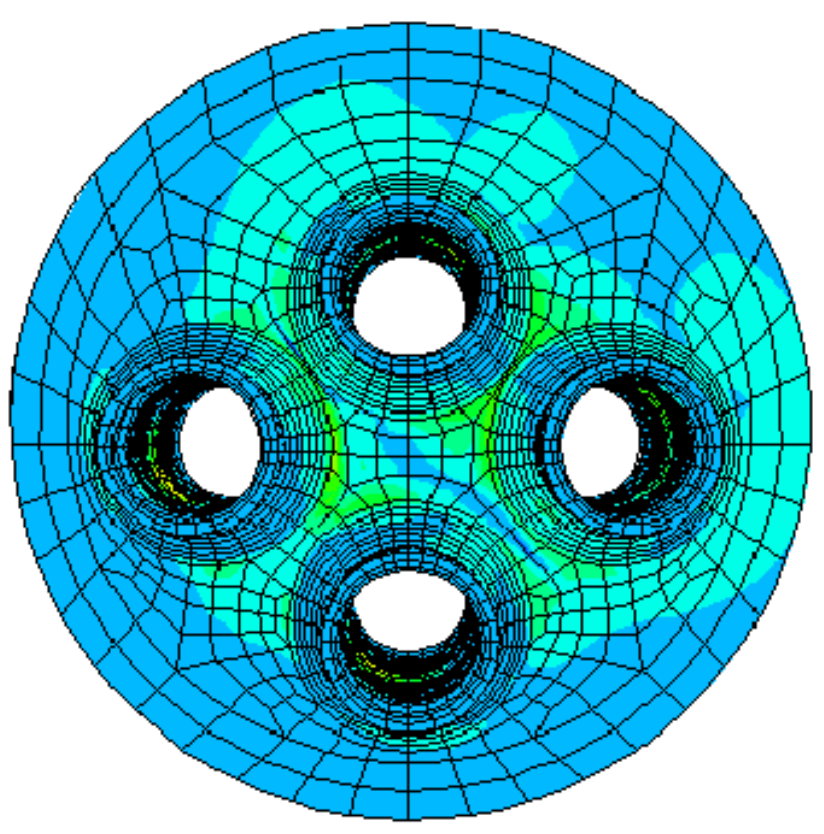

Fig.12 The contour of total strain range for the steady state cycle by LMM $\left(\Delta \bar{\varepsilon}=\bar{\varepsilon}\left(t_{\max }\right)-\bar{\varepsilon}\left(t_{\min }\right)\right)$ 

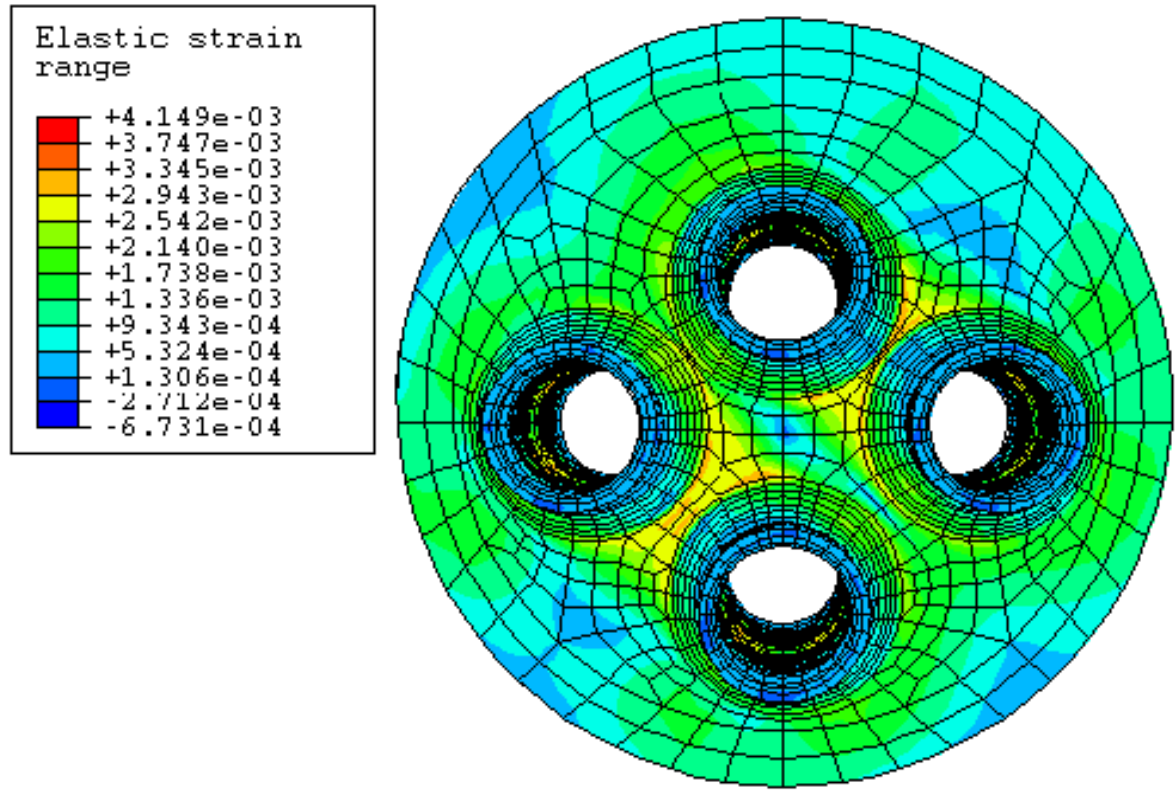

(a) Elastic strain range
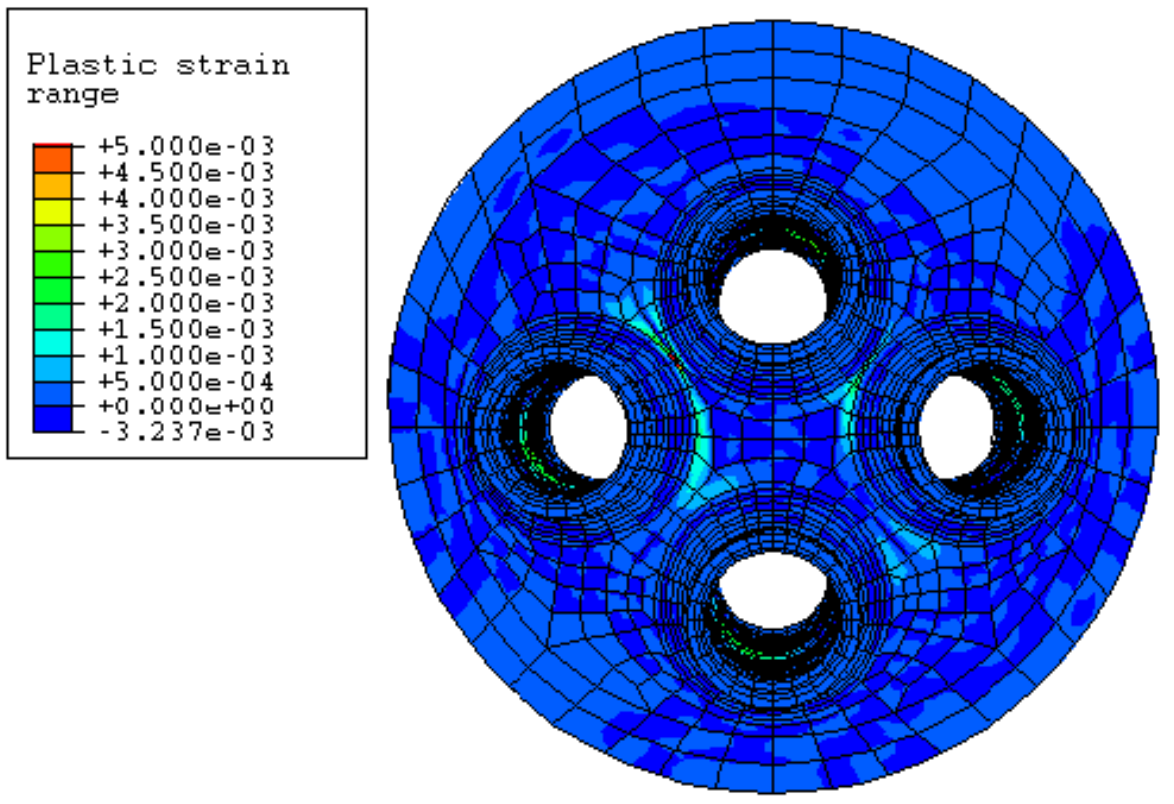

(b) Plastic strain range

Fig.13 The contour of elastic and plastic strain ranges for the steady state cycle by LMM 

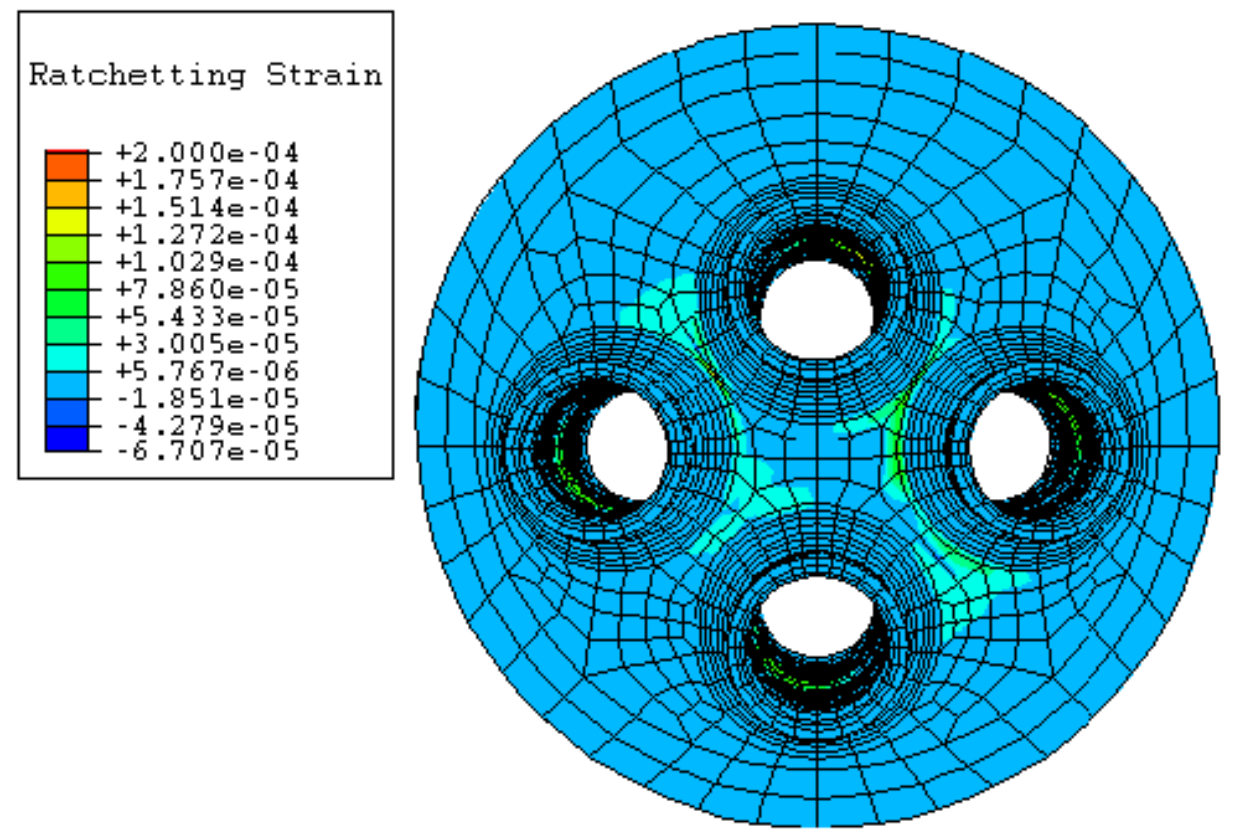

Fig.14 The contour of ratchetting strain over the steady state cycle by LMM 
Table 1 Variation of the coefficient of thermal expansion with temperature

\begin{tabular}{|c|c|c|c|c|c|c|c|c||}
\hline Temperature, ${ }^{\circ} \mathrm{C}$ & 20 & 100 & 200 & 300 & 400 & 500 & 600 & 700 \\
\hline $\begin{array}{c}\text { Thermal expansion coefficient } \\
\left(\times 10^{-6} / \mathrm{C}\right)\end{array}$ & 15.5 & 15.8 & 16.2 & 16.7 & 17.1 & 17.6 & 18.0 & 18.4 \\
\hline Specific heat $\left(\mathrm{kJ} / \mathrm{kg}^{\circ} \mathrm{C}\right)$ & 470 & 490 & 510 & 530 & 550 & 570 & 590 & 610 \\
\hline Thermal conductivity $\left(\mathrm{kW} / \mathrm{m}^{\circ} \mathrm{C}\right)$ & 0.01389 & 0.0151 & 0.0165 & 0.0180 & 0.0194 & 0.0208 & 0.0223 & 0.0237 \\
\hline
\end{tabular}


Table 2 Variation of Young's modulus $E$ with temperature

\begin{tabular}{|c|c|c|c|c|c|c|c|c||}
\hline Temperature, ${ }^{\circ} \mathrm{C}$ & 20 & 100 & 200 & 300 & 400 & 500 & 600 & 700 \\
\hline$E(\mathrm{MPa})$ & 198000 & 192000 & 185000 & 177000 & 170000 & 162000 & 155000 & 147000 \\
\hline
\end{tabular}


Table 3 Variation of $0.2 \%$ proof stress (MPa) with temperature

\begin{tabular}{|c|c|c|c|c|c|c|}
\hline Temperature, ${ }^{\circ} \mathrm{C}$ & 20 & 300 & 400 & 500 & 600 & 700 \\
\hline Tubeplate material certificate mean & 245 & 153 & 145 & 135 & 126 & 110 \\
\hline
\end{tabular}


Table 4 Comparison of Stress and Strain Range Calculations for Out of Phase

Temperature Oscillations (Node 3007)

\begin{tabular}{|c|c|c|}
\hline & Equivalent Strain Range (\%) & Equivalent Stress Range (MPa) \\
\hline 'Elastic' Analysis (R5SV) & 0.39 & 718 \\
\hline Inelastic R5SV & 0.51 & $\approx 450$ (at 10 cycles - still increasing) \\
\hline Elastic-Perfectly Plastic & 0.65 & 5300 \\
\hline R5 Volume 2/3 & 0.60 & 458 \\
\hline Linear Matching Method & 0.52 & 588 \\
\hline
\end{tabular}

